\title{
INNOVACIÓN Y MARKETING DEPORTIVO: \\ LA CREATIVIDAD
}

\author{
Javier Ramírez Perdiguero
}

Profesor de Publicidad y Comunicación Audiovisual. Universidad Francisco de Vitoria.

\section{Resumen}

En un mercado como el del deporte, calificado como global por su trascendencia -aunque inmovilista en normas y tradiciones- la innovación y la creatividad, como fuerzas de cambio, han de ser consideradas por la disciplina, el marketing deportivo, que maneja las herramientas que han de poner en sintonía los deseos y expectativas de los nuevos consumidores de deporte y los objetivos de las instituciones que lo ofertan en sus diversas formas.

\section{Palabras clave}

Creatividad - Innovación - Deporte - Marketing Deportivo

\begin{abstract}
In the sport market place -that has been cualified as global because of its transcendence- innovation and creativity, as driving forces of change, must be consider by sport marketing. This fairly new discipline manage the tools and abilities to meet the range of needs and expectations that can vary considerably among the different sport consumers groups, matching at the same time the sport organization goals.
\end{abstract}




\section{Key words}

Creativity - Innovation - Sport - Sport marketing

De la tensión creativa entre la cultura de un país (su percepción positiva o negativa de "lo nuevo", su voluntad o reticencia a innovar, etc.) y la disposición más o menos abierta de su estructura política, depende que su sociedad pueda modernizarse mediante el avance tecnológico o, al contrario, se estanque. (...) una de las preguntas más interesantes a hacerse en los próximos tiempos es si la creatividad es uno de los puntos fuertes de la sociedad española, y si esta creatividad

recibe el suficiente apoyo de la sociedad y del Estado para que se convierta en ciencia y en tecnología aplicada.

(Cornella 1999, 8)

\section{Introducción}

Muchas ideas, hábitos y comportamientos están sufriendo un proceso de cambio en los aspectos social, económico y tecnológico del mundo actual. La relación existente entre las crecientes necesidades y deseos del hombre actual y las posibilidades de satisfacerlas están del mismo modo en continuo cambio.

El deporte, como producto, participa de una manera singular en este proceso y protagoniza mucho tiempo en la existencia del hombre actual que exige constantes innovaciones y calidad en la satisfacción de sus necesidades y deseos en relación a todo tipo de productos, incluido el deporte.

Para Balbioni (1994), que definió el deporte como un servicio con características sociales particulares, el concepto de calidad se ha extendido con las crecientes necesidades del usuario y su elevada capacidad para satisfacerlas. En nuestra realidad económica y social, cualquier compañía del sector servicios no puede limitarse a satisfacer los estándares de los clientes. Los servicios siempre han sido considerados como "solventadores de problemas" en una visión limitada 
de los mismos que, actualmente, nada tienen que ver con la realidad actual donde se pueden crear y sugerir necesidades y proponer soluciones.

En nuestra opinión, las necesidades no son creadas sino su forma de satisfacerlas, y es aquí donde la creatividad adquiere un importantísimo valor. La inclusión de este concepto en la organización y gestión del deporte es ahora una realidad abierta a nivel internacional.

\section{La verdadera fuerza del cambio}

La creatividad, la originalidad, la búsqueda de nuevos caminos y soluciones ha sido una constante en la historia de la humanidad. Pero nunca como hasta ahora, la innovación ha dado tantos frutos en todos los terrenos; y el proceso es imparable, y esta capacidad se hace cada día más necesaria.

Cuando hace más de dos mil años Arquímedes dijo: "Dadme un punto de apoyo y moveré el mundo”, no era consciente de que lo que verdaderamente mueve hoy el mundo es la creatividad, terreno en el que él fue uno de los más destacadas con inventos, como el tornillo sin fin, o teoremas que han llegado hasta nuestros días.

Como han recogido algunos autores, "la verdadera fuerza que mueve al mundo es la innovación. No es una fuerza física, ni mecánica, pero es capaz de multiplicar la eficacia y la utilidad de todas las fuerzas conocidas. Seguramente, Arquímedes ya sabía, o al menos se imaginaba, que no se podía mover el mundo, como Mark Twain sabía que nunca tendría el monopolio de la tierra, pero ambos se imaginaban cómo podían cambiar las cosas si se daba el verdadero valor que tiene a la innovación. En definitiva, el valor que tiene la creatividad” (Baños 2001, 15-16). Las telecomunicaciones, la medicina, la arquitectura, el arte,... y, por supuesto, el marketing. La innovación se multiplica en todos los campos y, en el nuestro, actualmente, esta tendencia se ve potenciada por la saturación de productos (bienes, servicios e ideas), de medios de comunicación,... El público ya tiene que elegir entre dos o tres opciones, las posibilidades se multiplican, y en este incremento exponencial de oferta, el deporte no es ni mucho menos ajeno.

Hace cincuenta años el fútbol prácticamente no tenía competencia para disfrutar de una tarde de domingo; además, para ver el partido era imprescindible ir al campo, la otra opción era la radio. Con la televisión, la competencia se incrementa, pero poco, solamente se retransmite algún partido y, lógicamente, en contadas ocasiones, el de un equipo concreto. En pocos años, la situación se complica, la televisión digital multiplica la oferta, y los esfuerzos de los equipos por ocupar su espacio dentro de la mente del público, es decir, desarrollar su propia imagen corporativa que les 
proporciones una ventaja de partida ante sus competidores, se convierte en una tarea imprescindible, casi de supervivencia.

Pero lo peor, o lo mejor para amplios sectores de población, es que otros muchos deportes comienzan a levantar pasiones entre segmentos de población cada vez más amplios: baloncesto, balonmano, tenis, motociclismo,... son algunos ejemplos; y algunos que parecían destinados a los sectores socioeconómicos privilegiados -como el golf, el tenis, el esquí o la vela-, se convierten en actividades populares al alcance de todo el que lo desee en nuestro entorno.

Nacen nuevos deportes, algunos tan espectaculares como el surf, el parapente o los extremos. Y para alimentar tantos canales de televisión y tantos soportes destinados al deporte, todos ellos tienen cabida e interesan a segmentos de población cada vez más amplios

Finalmente, en este breve recorrido por la competencia del deporte, tenemos otra realidad: cada día el público tiene más posibilidades para disfrutar de sus momentos de ocio; antes era el cine, después dos canales de televisión, ahora cientos de cadenas que se ven en unas pantallas cada vez más sofisticadas. Los conciertos se multiplican poniéndose de moda la asistencia a otros tipos de eventos más allá de los deportivos.

Casi todas los hogares disponen de ordenadores, videojuegos, DVD, Internet,... El contrincante muchas veces ya no está en el terreno de juego, sino en otro terreno donde se juega algo más que un título de liga, se juega el futuro del deporte como negocio.

Las recientes olimpiadas de Atenas han demostrado que el deporte tiene que luchar con una dura competencia; Televisión Española ha tenido los derechos de uno de los mayores acontecimientos mundiales (en alguna cadena de televisión han comentado que solamente superado por las guerras), sin embargo, no ha sido capaz, a pesar de contar con la mejor herramienta y poner en las retrasmisiones a un número casi ilimitado de recursos, de situarse a la cabeza de la audiencia, viéndose superada por Antena 3.

Ante tanta oferta, el deporte es una opción muy interesante para todo aquel que quiera pasar grandes momentos de ocio, pero nunca lo ha tenido tan difícil para ganarse el favor del público.

Ante las cámaras, tenemos el deporte, el espectáculo que levanta pasiones entre millones de personas y, por supuesto, está el negocio, una maquinaria que mueve miles de millones de euros y que no se puede permitir perder asistentes a las canchas, ni, lo que es mucho más importante, audiencia ante las pantallas.

Los deportistas profesionales se convierten en estrellas mediáticas y su valoración va mucho más allá de su calidad técnica; su nombre, como la marca, les designa, pero con cada 
aparición, con cada actuación, ese nombre-marca, se va cargando de significados ocupando un espacio en la mente de "sus" públicos, hasta convertirse en imagen de marca. Michael Jordan cobraba cifras astronómicas como jugador, cobraba también como marca... y hoy sigue ganando por este concepto aunque ya no atraiga al público con sus mates. Ronaldo, en sus peores momentos de lesiones, mantenía ingresos multimillonarios sin tener que tocar un balón.

Para seguir manteniendo el valor de la marca, es necesario cambiar el terreno de juego, dejar de pensar exclusivamente en el deporte y pensar en la relación con sus públicos: de los deportistas con la gente, de los clubes con los aficionados, de los medios con su audiencia. Relaciones muy amplias, variadas y complejas que es necesario gestionar adecuadamente con eficacia y con mucha imaginación. En otras palabras: es imprescindible la creatividad en el marketing deportivo. Para mantener e incrementar el público que acuda los estadios, la audiencia que se sienta ante el televisor, los oyentes que cada día se acercan al deporte a través de la radio o los lectores de los diarios, es necesario aceptar las nuevas reglas del juego del mercado enfrentándose a una competencia que también quiere una cuota de mercado que, además, necesita para sobrevivir. Para todo esto hay que ofrecer algo más que la creciente competencia, diferenciarse y ganarse la fidelidad del público. Por otra parte, los grandes presupuestos de los clubes profesionales exigen buscar fórmulas que les permitan mantener su status.

Un modesto club de fútbol de regional puede tener suficiente para satisfacer sus necesidades puntuales con un calendario de "desnudos" artísticos donde posan los/las componentes de la plantilla. Un gran club de primera división necesita hacer muchas más cosas y, a ser posible, que no haya hecho antes nadie, es decir, innovar. Por eso la creatividad que tiene que estar, y de hecho está, presente en casi todos los terrenos de un marketing deportivo en el que ya desarrollan su actividad profesionales que tienen como objetivo pensar para cambiar las cosas. Comenta J. M. Ricarte que sólo "pensando se es capaz de elaborar la materia preparada para la percepción". Y el pensamiento productivo "No es tanto ver lo que aún nadie ha visto, como pensar lo que todavía nadie ha pensado sobre aquello que todos ven. Es decir, provocar la llegada de lo inesperado, de lo desconocido, provocar la creatividad: esa sorprendente comunicación con el inconsciente mediante la intuición y la imaginación. Es decir, esa atractiva capacidad de hacer sorprendente lo evidente" (2000, 73).

Crear es, por encima de todo, innovar. Ricardo Marín la define sencillamente como: "lo innovador y lo valioso, o si se quiere con una expresión más popular y ceñida, lo nuevo y lo bueno” (1991, 97). Otra definición interesante para nosotros es la que recoge Francisco García de J. C. Gowan, donde la creatividad es “aquel proceso que cristaliza en una obra nueva que resulta aceptada 
en virtud de su utilidad o satisfacción para un determinado grupo en un determinado momento temporal. Destaca, por tanto, los aspectos de proceso, novedad, utilidad para un determinado grupo y temporalidad" (1984, 42). Ciertamente, lo que necesitan muchas asociaciones y clubes para conseguir mantenerse en este competitivo mercado.

Por último una definición bastante interesante en nuestro caso es la que considera que la creatividad es "el proceso de formación de nuevas ideas o hipótesis, verificación de las mismas y comunicación de los resultados” (Curtis, Demos y Torrance 1976, 328). Y es interesante porque exige que haya algo nuevo; novedad que tiene que ser evaluada, lo que pone de manifiesto la importancia de definir unos objetivos de marketing claros para poder determinar si esa innovación ha servido para algo, o ha sido un fracaso; finalmente, incorpora una aspecto determinante para el marketing deportivo: la comunicación, ya que todo lo relacionado con deporte, directa o indirectamente, tiene que llegar al público que es, en definitiva, quien tiene la última palabra.

Si analizamos brevemente el papel de la creatividad en el mundo del deporte -en realidad, en el complejo mundo del marketing deportivo- la descubrimos jugando un papel fundamental en todos los terrenos: en el producto-deporte que se adapta a los gustos del mercado; en la distribución-difusión buscando nuevas vías para llegar al público; en la comunicación-publicidad con campañas creativas algunas de ellas inolvidables; y hasta en el precio-entrada, obteniendo ingresos atípicos que, definitivamente, cada día son más típicos.

Veamos cada unos de estos elementos un poco más detenidamente:

La creatividad se aplica al producto, porque tiene que adaptarse a los gustos de los públicos, como sucede con cualquier otro producto o servicio; se cambian la reglas para que todo sea más ameno como reducir el tiempo de posesión en el baloncesto europeo para incrementar el ritmo de las jugadas o permitir más cambios en el fútbol para tener a los jugadores más frescos y activos. Pero además, como cualquier empresa, diversifican la “gama de productos”, ahora no sólo es necesario tener secciones deportivas (fútbol, baloncesto, balonmano,...), ahora también los deportistas forman parte de esta gama (marcas dentro de la súper marca que es el club) con "todo" a la venta: su camiseta, su número, su fotografía,... y también es obligatorio tener productos de marchandising: relojes, llaveros, mecheros,.... todo está en venta y, desde luego, muchos clubes de todo el mundo lo venden muy bien.

En la distribución, los espectadores que asisten al campo son un segmento marginal de consumidores, hay que hacer llegar a la gente el producto por otros medios: televisión radio, Internet $\mathrm{y}, . .$. por supuesto, si un medio de comunicación gana dinero con "mi gama de productos", ¿por qué no es posible venderlo directamente creando un canal de televisión propio? Real Madrid, Barcelona 
y otros grandes clubes tienen sus propios soportes de comunicación dentro de una oferta digital cada día más abundante en todos los países.

Los estrechos límites del campo se agitan en un mundo globalizado llegando a rincones donde nunca antes habían llegado. Japón o China se han convertido en terreno de juego del marketing deportivo que obliga a los jugadores a giras interminables para conseguir abrir nuevos mercados a toda la gama de productos; se juegan unos amistosos antes de comenzar la temporada y se venden partidos, o camisetas que son unos ingresos tan interesantes como cualquiera, durante el resto de la temporada. En un mercado globalizado, el marketing deportivo también se tiene que planificar a nivel global, desarrollando proyectos para otros públicos y para otros intereses.

Si el mercado es global y muy competitivo, la comunicación de los clubes también tiene que cambiar para adaptarse a la nueva situación; no se trata de convencer a los hinchas de la ciudad para que se hagan socios y vayan al campo, ahora hay que dirigirse a todo el mundo para que compren muchas cosas, y desarrollar una imagen corporativa valorada y deseada a miles de kilómetros de distancia. Es necesario utilizar otros medios de comunicación, llegar a otras mentalidades completamente diferentes, y hacerlo de una forma inmediata. Además, lo tiene que hacer rodeado de miles de carteles de todo tipo de espectáculos, teniendo presente que hay muchos equipos en la misma situación y que la audiencia puede elegir entre muchísimas retransmisiones deportivas. El mercado exige aquí también creatividad para comunicarse con esos públicos, a través de una página web, del canal de televisión como acabamos de comentar o de campañas tan originales como las del Atlético de Madrid para captar socios: saliendo del infierno o recurriendo al hermanamiento de enemigos en plena Guerra Civil por una pasión común: el Atlético de Madrid.

También para llegar “tan lejos” es imprescindible utilizar otras fórmulas como las Relaciones Públicas aprovechando el impacto de las contrataciones, de la organización de eventos pensando en la repercusión que tendrán en los medios de comunicación de todo el mundo, también se organizan cursos de lo más variado, se convocan becas, se organizan visitas e incluso, los jugadores de baloncesto del Joventud buscan espectadores recorriendo las casas de la ciudad. Todo lo que haga falta para llegar a la gente y comunicarse con sus públicos.

Finalmente, el precio; de nuevo la entrada vuelve a ser lo de menos, como lo demuestra la asistencia a los estadios durante las Olimpiadas. Hay otras fórmulas mucho más interesantes para mejorar la cuenta de resultados de los clubes. Se cobra a través de la televisión, de las giras y de los compromisos de los deportivos, del espacio disponible en las camisetas con patrocinios multimillonarios, y también se consiguen grandes sumas de dinero con la completa gama de productos derivados, como ya hemos comentado, a partir de sus jugadores, las marcas más valiosas 
del club. Productos por los que se llegan a pagar cantidades de dinero bastante elevadas, como sucede con todo lo que ha "tocado" una estrella; como decía Séguèla, una estrella nos puede vender lo que quiera y cobrarnos lo que desee porque no nos está vendiendo un producto, nos está vendiendo un sueño, y los sueños, al contrario que los objetos, no tienen precio. Esto lo están aprendiendo rápidamente los dirigentes deportivos que multiplican el valor de una camiseta por ser del equipo de un famoso jugador-estrella.

Por último, también podemos añadir las novedades que presentan las personas que están entrando en el deporte como un elemento más del marketing. Los clubes se encargan de contratar, cada día más, gente con un perfil más vendedor, capaz de llegar más y mejor a los aficionados. Antiguos deportistas queridos por la afición para el banquillo o para las oficinas, y estrellas actuales para saltar al campo cada partido y levantar pasiones entre espectadores y teleespectadores. Una plantilla muy completa para alcanzar a todos los públicos y conseguir unos objetivos de marketing cada vez más ambiciosos.

Un gran club no es ya una simple sociedad deportiva compuesta por profesionales del deporte en el campo, amantes del deporte en la gestión y aficionados al deporte en las gradas. Ahora tienen marcas-estrella en el campo (de esas que son capaces de seducir y vender sueños), profesionales de la gestión y de marketing en los despachos y en el palco (lugar especialmente importante para sustentar el negocio), y todo tipo de aficionados en la grada y ante el televisor (aficionados al deporte, a la crónica rosa, a los escándalos, a los recientemente puestos de moda hombres metrosexuales,...).

En resumen, son necesarios demasiados cambios, demasiadas adaptaciones, como para perder un tren tan valioso como el de la creatividad en un terreno tan reciente y complejo como el del marketing deportivo; un mercado el que se mueven muchos intereses y que cada día exige más y más recursos para contar con unas estrellas que saben el valor que tienen como imagen de marca para los clubes de cualquier deporte profesional. 


\section{Bibliografía}

- A.T. KEARNEY, 2003: Que los Juegos comiencen. Encarando los temas y retos en la nueva industria del deporte, Marketing and Communication, Chicago.

- BAÑOS GONZÁLEZ, M., 2001: Creatividad y publicidad, Ediciones del Laberinto, Madrid.

- BALBONI, A., 1994: A new management for a new concept of sport, $2^{\text {nd }}$ EASM Congress, Florence.

- CORNELLA, A., 1999: En la sociedad del conocimiento, la riqueza está en las ideas, trabajo no publicado.

- CURTIS, DEMOS y TORRANCE, 1976: Implicaciones educativas de la creatividad, ANAYA, Salamanca.

- GARCÍA GARCÍA, F.. 1984: Estudios de creatividad en niños de edad escolar, Universidad Complutense, Madrid.

- $\quad$ KOTLER, Ph. y TRIAS DE BES, F., 2004: Marketing Lateral, Pearson Educación, Madrid.

- MARÍN, R. y DE LA TORRE, S., 1991: Manual de creatividad. Vicens Vives, Barcelona.

- RICARTE, J.M., 2000: Líneas de investigación en la comunicación persuasiva, en Temes de Disseny, número 17, Elisava Edicions, Barcelona. 